DOI: http://dx.doi.org/10.9771/rc-ufba.v14i2.34965

\title{
GOVERNANÇA CORPORATIVA: TENDÊNCIAS NAS PESQUISAS BRASILEIRAS
}

\author{
CORPORATE GOVERNANCE: TRENDS IN BRAZILIAN RESEARCH
}

\author{
Diego Rodrigues Boente ${ }^{1}$ \\ Fucape Business School \\ diegoboente@gmail.com
}

\author{
Andria Fabricia de Lima Cunha \\ Fucape Business School \\ andria.lima@gmail.com
}

\author{
Adriana Lins de Gusmão Vila Nova \\ Fucape Business School \\ adriana.lins@ifal.edu.br
}

\author{
Tamara Gama Cavalcante \\ Fucape Business School \\ tamaragcavalcante@ hotmail.com
}

\begin{abstract}
RESUMO
O objetivo do trabalho é verificar a evolução da produção acadêmica sobre governança corporativa, no período de 2014 a 2018, delimitada aos periódicos brasileiros das áreas de administração e contabilidade. A metodologia utilizada foi um estudo bibliométrico em uma amostra de 71 artigos. A pesquisa teve caráter descritivo e documental, utilizando dados da Coordenação de Aperfeiçoamento de Pessoal de Nível Superior (CAPES). Como resultado, percebeu-se que o ano que apresenta o maior número de publicações foi o ano de 2014; que apenas quatro autores foram mais produtivos e que a produção acadêmica sobre o tema se mostra concentrada nas regiões sul e sudeste. A quantidade de autores por artigo mais comumente encontrada foi de três autores, sendo a maioria das pesquisas científicas realizadas através da abordagem quantitativa. Pode-se concluir que a produção científica sobre o tema pode ter entrado em um período de estagnação ou esgotamento. A presente pesquisa contribui com a discussão sobre a temática ao descrever os principais aspectos dos trabalhos acadêmicos mais recentes, permitindo evidenciar tendências e reflexões.
\end{abstract}

Palavras-chave: Governança corporativa. Teoria da agência. Estudo bibliométrico. Produção acadêmica.

\footnotetext{
${ }^{1}$ SCS Quadra 07 Bloco A nº 100, Sala 1305 - Edifício Torre do Pátio Brasil - Brasília/DF - CEP 70307-901.
} 


\begin{abstract}
The objective of this paper is to verify the evolution of academic production on corporate governance, from 2014 to 2018, limited to Brazilian journals in the areas of administration and accounting. The methodology used was a bibliometric study in a sample of 71 articles. The research was descriptive and documentary, using data from the Coordination of Improvement of Higher Education Personnel (CAPES). As a result, the year with the highest number of publications was 2014; that only four authors from the south and southeast regions were more productive and that the academic production. The number of authors per article most commonly found was three authors; most of the scientific research conducted through the quantitative approach. We concluded that scientific production on the subject might have entered a period of stagnation or exhaustion. The present research contributes to the discussion on the theme by describing the main aspects of the most recent academic works, allowing to show trends and reflections.
\end{abstract}

Keywords: Corporate governance. Agency theory. Bibliometric study. Academic production.

\title{
1 INTRODUÇÃO
}

Com o desenvolvimento das organizações que pouco a pouco deixaram de ser familiares e passaram para um modelo de participações acionárias, houve a separação entre propriedade e controle. As empresas cresceram em um mundo empresarial moderno, com forte globalização e fluxo constante de informações, existe cada vez mais mobilidade e interconexão entre empresas.

Esta separação ocorreu devido à complexidade das operações que ocorrem nas empresas, fazendo surgir, com isto, especialistas para executar as gerências dos setores operacionais da empresa. Desta forma, a gerência das empresas começou a ser executada por profissionais especialistas, o que aumentou a possibilidade do desenvolvimento patrimonial dessas empresas. Berle e Means (1932) abordam questões a respeito da separação do direito de propriedade e de controle.

Um sistema de Governança Corporativa surge justamente para procurar resolver os conflitos de agência. A relação entre Teoria da Agência e Governança Corporativa é percebida nos trabalhos iniciais de Berle e Means (1932), considerado um marco inicial em Governança Corporativa. No entanto, esta temática passou a ser investigada com maior profundidade no ano de 2002, como consequência da divulgação de descobertas de fraudes contábeis que envolviam grandes corporações.

Sobre governança, Chagas (2007) enfatiza ainda que, em essência, trata-se de um sistema que, usando principalmente o conselho de administração, a auditoria externa e o conselho fiscal, estabelece regras e poderes para conselhos, comitês, diretoria e outros gestores, procurando prevenir abusos de poder e criando instrumentos de fiscalização, princípios e regras que possibilitem uma gestão eficiente e eficaz. Entende-se, portanto, assunto de interesse relevante para os que atuam nas áreas de controladoria e contabilidade.

Demirbas e Yukhanaev (2011) têm enfatizado que a contabilidade e/ou controladoria pode ser uma ferramenta de redução desses conflitos de agência. Com seu complexo de melhores técnicas, auxilia para que assimetria informacional seja minimizada, visto que tem por finalidade elevar a transparência e a confiabilidade das ações organizacionais, protegendo investidores, empregados e credores.

No Brasil, a expressão "governança corporativa" está relacionada com o desenvolvimento do mercado acionário a partir dos anos 1970, quando foi criada a lei das 
Sociedades Anônimas (Lei $\mathrm{n}^{\circ}$ 6.404/1976), como uma das alternativas. Todavia, surgiu em 1995, o Instituto Brasileiro de Governança Corporativa (IBGC), organização precursora no tema de governança no país. O IBGC, organização sem fins lucrativos, é a principal referência do Brasil para o desenvolvimento das melhores práticas de Governança Corporativa (IBGC, 2019).

Com o intuito de dar proteção legal e institucional aos acionistas minoritários, a Bolsa de Valores de São Paulo instituiu no ano de 2000 níveis diferenciados de governança corporativa para as empresas que se comprometem, de forma voluntária, a aderirem as melhores práticas de Governança Corporativa e Disclosure de suas informações em nível superior ao exigido da legislação brasileira (COSTA, 2013).

$\mathrm{Na}$ academia, o debate continua a suscitar muitas contribuições teóricas e práticas desde então. Contudo, não há consenso entre os autores se as boas práticas de governança corporativa tendem a melhorar o desempenho da organização (OLIVEIRA et al, 2017). Assim, a presente pesquisa contribui com a discussão sobre a temática ao descrever os principais aspectos dos trabalhos acadêmicos mais recentes como o ano da publicação, periódico, região, autor, Instituição de Ensino Superior (IES) e abordagem metodológica, permitindo evidenciar tendências e reflexões.

Justifica-se ainda que as pesquisas bibliométricas permitem conhecer um determinado assunto, mesmo que este já tenha certa maturidade no meio acadêmico e profissional, como é o caso de Governança Corporativa, conforme afirma Ribeiro e Santos (2015).

Diante do exposto, elaborou-se a seguinte questão de pesquisa: Qual é o perfil da produção acadêmica sobre governança corporativa, no período de 2014 a 2018 ?

O objetivo do trabalho é verificar a evolução da produção acadêmica sobre governança corporativa, no período de 2014 a 2018, delimitada aos periódicos brasileiros das áreas de administração e contabilidade. Para tanto, realizou-se uma pesquisa descritiva e documental.

Sem embargo, a importância e a possibilidade de aplicação de Leis da Bibliometria, tais como Lei de Lotka, Lei de Bradford, Lei de Zipf, e tantas outras, não se constituíram em objeto deste trabalho, optando-se por uma apresentação descritiva dos achados.

Além da introdução, este estudo apresenta mais quatro seções. Na Seção 2, é apresentado o referencial teórico e normativo sobre o tema, trazendo os principais conceitos que envolvem a governança corporativa, os conflitos de agência e a contabilidade. A metodologia utilizada no estudo é demonstrada na Seção 3. Na Seção 4, são apresentados os resultados obtidos a partir da análise realizada. As considerações finais do estudo e a sugestão para futuras pesquisas são apresentadas na Seção 5, seguidas das referências.

\section{REFERENCIAL TEÓRICO}

\subsection{Governança Corporativa}

Segundo o Instituto Brasileiro de Governança Corporativa (IBGC, 2019), governança corporativa é o método pelo qual as organizações e demais entidades são dirigidas, supervisionadas e incentivadas, envolvendo os relacionamentos entre sócios, conselho de administração, diretoria, órgãos de fiscalização e controle e demais partes interessadas.

O IBGC (2019) elaborou o Código de Melhores Práticas de Governança Corporativa com o intuito de resolver problemas como: instituição da governança corporativa nas empresas, vistoriando, a partir da criação do código, a inserção contínua dessas práticas na cultura das organizações. Esse código tem como principal propósito guiar e regular as práticas de governança no Brasil com base nas necessidades de empresas e das expectativas da sociedade para com essas. 
De acordo com o IBGC (2019), os princípios básicos de Governança Corporativa são: (i) transparência: Consiste no desejo de disponibilizar para as partes interessadas as informações que sejam de seu interesse e não apenas aquelas impostas por disposições de leis ou regulamentos; (ii) equidade: Caracteriza-se pelo tratamento justo e isonômico de todos os sócios e demais partes interessadas (stakeholders).; (iii) prestação de contas (accountability): Os agentes de governança devem prestar contas de sua atuação de modo claro, conciso, compreensível e tempestivo, assumindo integralmente as consequências de seus atos e omissões e atuando com diligência e responsabilidade no âmbito dos seus papéis; e (iv) responsabilidade corporativa: Os agentes de governança devem zelar pela viabilidade econômico-financeira das organizações, reduzir as externalidades negativas de seus negócios e suas operações e aumentar as positivas, levando em consideração, no seu modelo de negócios, os diversos capitais (financeiro, manufaturado, intelectual, humano, social, ambiental, reputacional etc.) no curto, médio e longo prazos.

A Governança Corporativa proporciona aos acionistas o gerenciamento da empresa e a adequada fiscalização dos agentes. A boa governança corporativa garante equidade aos sócios, transparência e responsabilidade pelos resultados (accountability).

Apesar de a Governança ter maior rigidez legal, como por exemplo a Instrução CVM n ${ }^{\circ}$ 586, de 8 de junho de 2017, que se aplica às companhias de capital aberto, qualquer empresa deveria adotar as boas práticas de Governança Corporativa. De acordo com estudos de Klapper e Love (2004) ela é um meio de agregar valor à empresa, haja vista que o mercado julga serem mais valorizadas e com indícios de uma gestão mais profissional, as empresas com governança. Sendo assim, ela tem uma forte importância na capacidade da empresa de gerar capital para o seu negócio, quanto maior a confirmação das informações relativas à governança corporativa, maior é o valor representativo da entidade para o mercado.

De acordo com os estudos de Jensen e Meckling (1976), pode-se entender a relação de agência como um contrato no qual uma ou mais pessoas (principal) irá empregar outra pessoa (o agente) para que ele realize algum serviço ou trabalho em seu favor, envolvendo delegação de autoridade de decisão para o agente. Os autores falam ainda que existe uma boa razão para que se acredite que o agente não irá se comportar da maneira esperada pelo principal, pelo fato de ambos serem maximizadores de utilidade.

De acordo com Jensen e Meckling (1976), a Teoria de Agência procura explicar os conflitos de interesses que podem surgir entre um principal e um agente. Esses conflitos são inevitáveis, porque, inicialmente, o agente, em troca de uma remuneração, teria de atuar de acordo com os interesses do principal, todavia, isto poderá não acontecer porque o agente também vai tentar maximizar a sua própria função utilidade, ou seja, agirá motivado, exclusivamente por seus interesses. $\mathrm{O}$ agente e principal são pessoas diferentes e, sendo assim, os interesses daquele que administra a propriedade nem sempre estão ordenados com os dos proprietários e/ou acionistas. Desta forma, no conflito de agência ocorre a concordância entre o comportamento desejado pelo principal e o comportamento apresentado pelo agente.

Os conflitos de agência podem envolver: (i) acionistas (principal): desejam, na maioria das vezes, retorno sobre o capital investido, de preferência em curto prazo; e (ii) diretores (agentes): podem desejar, por exemplo, reinvestir o lucro, visando ao crescimento da empresa ao longo prazo.

De acordo com os estudos de Jensen e Meckling (1976), a divergência de interesses entre estes levam as organizações a incorrer em custos de oportunidade, tais como os gastos para monitoramento do comportamento dos administradores e as perdas residuais. As perdas residuais, por sua vez, representam cada unidade monetária equivalente a redução de bem-estar do principal em função das divergências existentes com o agente.

Segundo Barney e Hesterly (2004), para diminuir o problema de agência, a administração deve ser cercada por um sistema de controle de gestão, no qual os controles 
devem ser feitos de forma integrada e unificada. Um plano de incentivo a penalização dos agentes por omissão no trabalho e por oportunismo é considerado como instrumento ideal para muitos proprietários. Isto, no entanto, mostra-se bastante difícil de pôr em prática, por expor os agentes a riscos que eles considerariam inaceitavelmente altos. "A racionalidade limitada, que está dentro da teoria da agência e da teoria dos custos de transação, é, de certo modo, de extrema relevância para o monitoramento dos agentes" (Moraes, 2015, p. 35).

Pode-se dizer que de acordo com a literatura do principal-agente se volta para a análise de como o acionista estabelece um contrato que motive o agente a agir de acordo com o interesse do principal. Sugerindo e propondo mecanismos de como assegurar a construção de contratos que sejam os mais eficientes possíveis para a solução de problemas.

Existe dentro dos custos de agência uma diferença entre o custo da ação e o custo do resultado. Merchant e Van Der Stede (2007) afirmam que o custo da ação envolve a adoção de medidas que assegurem que os trabalhadores irão desempenhar ações que beneficiarão a organização e que não desempenharão ações que sejam prejudiciais à mesma. Nesse caso, os custos são diretamente observáveis e podem se manifestar de diversas formas, como: benefícios/mordomias que o agente ficará inclinado a obter para si em contrapartida de sua dedicação ao trabalho, como por exemplo, uma sala maior, automóvel de luxo, escritório caro, motorista, dentre outras ações que minimizam a riqueza do principal.

Já os custos do resultado, Oliveira (2011) diz que a organização não determina quais ações devem ser tomadas pelos trabalhadores, cabe a eles escolher quais ações serão necessárias para se alcançar os resultados desejados pela organização. Esses custos não são diretamente observáveis, pois não é exercido diretamente sobre o trabalhador, mas sim sobre o resultado de suas ações. Assim, por exemplo, quando o agente opta por aceitar projetos de investimentos com VPL mais baixos, até mesmo projetos com VPL que projetem um pouco de prejuízo. Pois, sabe-se que a remuneração da diretoria tende a aumentar com o aumento da empresa, assim a pequena perda de lucratividade em suas ações pode ser menor do que o aumento de seu salário. Muitos agentes tendem a pensar que trabalham de forma excessiva, com muitas horas dedicadas a empresa, abdicando de momentos de sua vida pessoal em prol da organização.

\subsection{Produção científica sobre governança corporativa}

Segundo Machado, Fernandes e Bianchi (2016), a contabilidade é utilizada para diversas finalidades e pode atuar tanto como instrumento de avaliação dos agentes, como também na redução da assimetria, por meio de seus relatórios, com informações societárias e gerenciais. Assume-se como premissa que o contador, no exercício de suas funções, atua com isenção, evitando conceder privilégios ao principal ou ao agente.

Na perspectiva da Teoria do Agenciamento, os sistemas de informações contábeis são vistos como sistemas de monitoramento que produzem informações no qual o principal (proprietário) e o agente (gerente) baseiam suas relações. A informação contábil é fundamental para a análise de performance dos gestores, para redução dos conflitos de agência e da assimetria informacional entre principal e agente, bem como para o processo de feedback e predição de eventos futuros da organização. Ainda, a contabilidade caracteriza-se como instrumento de accountability, contribuindo para que a governança corporativa seja ativa e eficaz nas organizações (MARTINEZ, 1998; MACHADO; FERNANDES; BIANCHI, 2016).

O sistema de contabilidade financeira ou societária pode ser averiguado à luz da redução de assimetria informacional entre investidores e agentes envolvido no conflito de agência. As técnicas utilizadas pela contabilidade, principalmente as gerenciais, tais como: orçamentos, sistemas e métodos de custeio, não são apenas técnicas de verificação objetiva de performance, mas sim instrumentos de poder e de controle organizacional. 
Ainda de acordo com Machado, Fernandes e Bianchi (2016), nesse contexto entende-se que a contabilidade atende à teoria da agência, pois cabe à contabilidade importante papel quanto à mensuração, informação e feedback que envolve os participantes nos contratos. Iudícibus e Lopes (2004) afirmam que não é possível uma única forma de a contabilidade atender a todos os usuários e participantes nos contratos, tendo em vista que há interesses distintos, sendo necessário que haja uma adaptação a cada categoria de usuários de forma que a contabilidade possa fornecer informações efetivamente úteis.

A Bolsa de Valores de São Paulo (atualmente Brasil, Bolsa, Balcão - B3) criou níveis classificatórios de acordo com o nível de governança corporativa de cada companhia - uma espécie de "selo de qualidade" para melhorar as práticas de governança corporativa no Brasil, conhecido como Novo Mercado e Níveis 1 e 2. As empresas que aderem ao Nível 1 se comprometem, principalmente, com melhoras na prestação de informações e com a dispersão acionária. Empresas que negociam ações no Nível 2 comprometem-se a cumprir as regras aplicáveis ao Nível 1 e, em acréscimo, um conjunto mais amplo de práticas de governança corporativa, relativas aos direitos societários dos acionistas minoritários. Por fim, empresas aderentes ao Novo Mercado, além de cumprir as regras dos Níveis 1 e 2, exige-se que o capital social da empresa seja composto somente por ações ordinárias (B3, 2019).

Empresas que divulgam suas informações e adotam os princípios de governança corporativa poderão ser visualizadas, no mercado financeiro, como de menores riscos, assim atraem mais investidores e estes, ao investirem seu capital na companhia, contribuem para seu melhor desempenho financeiro. Klapper e Love (2004) utilizaram os rankings de governança elaborados pelo Banco Credit Lyonnais Securities Asia com o objetivo de investigar melhor o relacionamento entre governança e desempenho. Os autores perceberam que as empresas classificadas no índice de governança obtiveram melhor desempenho operacional e maiores retornos acionários.

Correia (2008) percebeu em seu estudo que, quando a empresa possui um sistema de governança de qualidade, os indicadores de confiança dos investidores são mais altos, tem maiores possibilidades de crescimento, as ações da companhia tendem a ser mais atrativas e a apresentar maior valorização de mercado.

Sonza e Kloekner (2014) identificaram evidências positivas da eficiência das empresas de capital aberto sobre a governança corporativa, evidenciando as condições particulares das finanças corporativas no Brasil, tais como (i) alta sobreposição propriedade-direção; (ii) conselhos de administração de baixa efetividade; (iii) em grupos familiares, os papéis dos acionistas, dos conselhos e da direção não são bem definidos; (iv) existe pouca clareza quanto à relação benefício-custo da boa governança; (v) baixa eficácia dos conselhos de administração; e (vi) indícios de conflitos de interesses, relativizados por incentivos explícitos e implícitos.

Espera-se com a governança ganhos alcançados com a redução dos riscos e o maior acerto nas decisões, porém pode-se perceber que o custo de se manter uma empresa dentro dos padrões orientados é muito alto. Desta forma, grande parte das empresas, principalmente de pequeno porte, não suportam e seguem com seus padrões de controle próprios ou adaptados, estruturados ou não.

\section{METODOLOGIA}

Para a análise de como se encontra a situação atual da discussão sobre governança, foi pesquisado dentro do portal de periódicos da Coordenação de Aperfeiçoamento de Pessoal de Nível Superior (CAPES) os artigos que continham no título a palavra "Governança Corporativa", abarcando o período de 2014 a 2018. Foi encontrada uma listagem inicial com 89 artigos "revisados por pares" distribuídos em diversas revistas científicas distintas. Após a eliminação de artigos em duplicidade (versões em diferentes idiomas), foi identificado um 
artigo publicado na Revista Mexicana Contaduría y Administracion. Houve a opção de excluílo (em todas as suas 3 versões) para que a análise fosse realizada apenas dentro do cenário brasileiro.

A amostra contemplou 71 artigos distribuídos em 31 revistas científicas distintas. A partir daí, foi realizada uma análise bibliométrica, possibilitando a verificação dos aspectos quantitativos e a disseminação da pesquisa acerca da governança corporativa no Brasil.

As revistas foram relacionadas a suas instituições responsáveis. Através da utilização da estatística descritiva, foram tabulados os dados e elaboradas tabelas e figuras para análise dos resultados com apoio do software Microsoft Excel®. As tabelas e as figuras foram construídas de modo a abranger diferentes focos de análise, sendo eles: ano da publicação; periódico; região; autor, Instituição de Ensino Superior (IES) e abordagem metodológica. Desta forma, possibilitou maior entendimento e estudo sobre a situação atual das publicações sobre o tema Governança Corporativa no país, no período considerado.

\section{ANÁLISE DOS RESULTADOS}

A Figura 1 apresenta o número de artigos publicados sobre o tema governança corporativa, no período delimitado pela pesquisa. O ano de 2014 mostra-se com maior relevância com relação a quantidade de publicações (21 artigos) e 2018 o ano com o menor número de publicações, com apenas 8 artigos. O ano de 2017 demonstrou um crescimento na produtividade sobre governança corporativa, no entanto, não houve continuidade. Os anos de 2014 e 2015 representam 56\% de toda produção científica dentro do período estudado, o que pode sugerir a estagnação ou esgotamento do tema.

Figura 1 - Distribuição da produção científica em Governança Corporativa

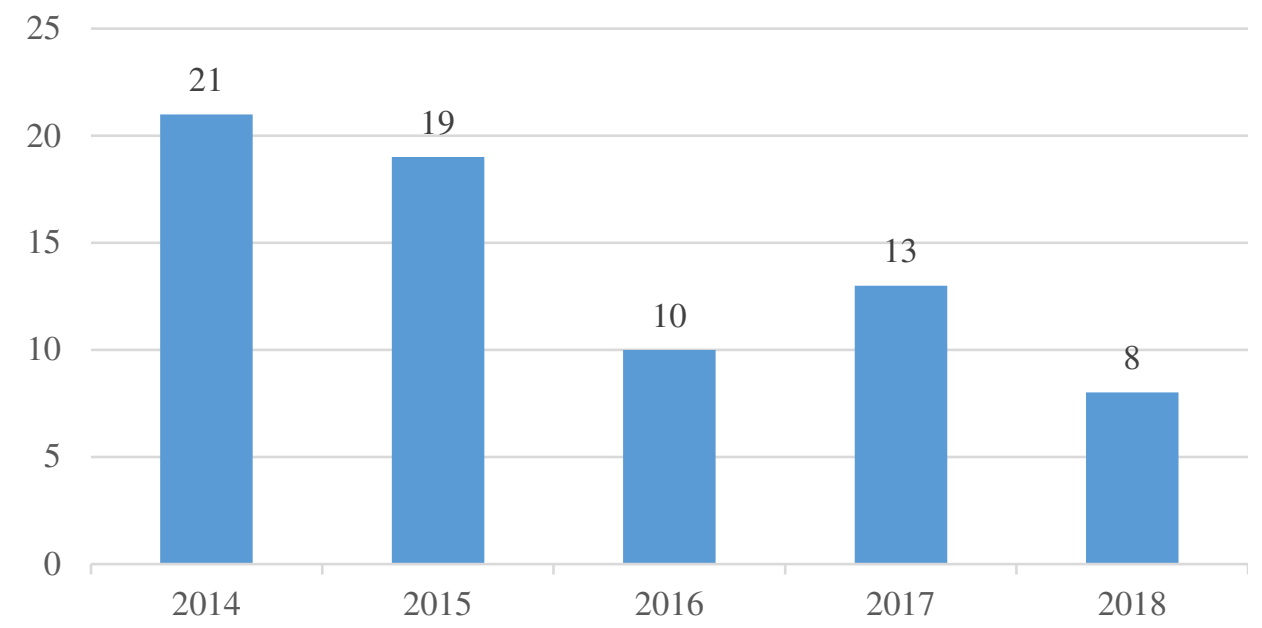

Fonte: Dados da pesquisa.

Na Tabela 1, consideram-se os periódicos nacionais, da área de Administração e Contabilidade, com maior número de artigos publicados sobre o tema Governança Corporativa. Foram identificados 71 artigos distribuídos entre 31 periódicos, dos quais se destacam apenas 3, sendo elas Revista Contemporânea de Contabilidade (com 8 publicações), REGE - Revista de Gestão (com 7 publicações) e Revista de Gestão, Finanças e Contabilidade (com 6 publicações), equivalendo a um percentual de quase 30\% de todos os trabalhos publicados, demonstrando que há forte concentração das publicações científicas.

Pode-se perceber também que 15 revistas publicaram apenas 1 artigo sobre o tema, representando um percentual de $21,15 \%$ da produção científica; 8 revistas publicaram apenas 2 
artigos, representando um percentual de $22,55 \%$ da produção científica, e apenas 8 revistas publicaram acima de 2 artigos, totalizando 56,3\% das publicações, sendo as principais já mencionadas anteriormente.

Tabela 1 - Produção científica por periódico

\begin{tabular}{|c|c|c|c|}
\hline Periódico & Artigos & IES & $\%$ \\
\hline Revista Contemporânea de Contabilidade & 8 & UFSC & 11,27 \\
\hline Revista de Gestão (REGE) & 7 & USP & 9,86 \\
\hline Revista de Gestão, Finanças e Contabilidade & 6 & UNEB & 8,45 \\
\hline Revista Ambiente Contábil & 4 & UFRN & 5,63 \\
\hline Revista de Administração Faces & 4 & FUMEC & 5,63 \\
\hline Revista de Administração, Contabilidade e Economia (Race) & 4 & UNOESC & 5,63 \\
\hline Revista Evidenciação Contábil \& Finanças & 4 & UFPB & 5,63 \\
\hline Revista Ciências da Administração & 3 & UFSC & 4,23 \\
\hline Revista de Administração Mackenzie (RAM) & 2 & UPM & 2,82 \\
\hline Revista Ibero-Americana de Estratégia (RIAE) & 2 & UNINOVE & 2,82 \\
\hline Revista Metropolitana de Sustentabilidade & 2 & FMU & 2,82 \\
\hline Revista Contabilidade \& Finanças & 2 & USP & 2,82 \\
\hline Revista Brasileira de Finanças & 2 & USP & 2,82 \\
\hline Revista do Instituto de Ciências Econômicas Sinergia & 2 & FURG & 2,82 \\
\hline Revista de Gestão e Tecnologia Navus & 2 & SENAC & 2,82 \\
\hline Revista de Administração de Roraima & 2 & UFRR & 2,82 \\
\hline Revista Podium Sport, Leisure and Tourism Review & 1 & UNINOVE & 1,41 \\
\hline Revista Brazilian Business Review & 1 & FUCAPE & 1,41 \\
\hline Revista Electronica de Sistemas De Informação (Resi) & 1 & UFSC & 1,41 \\
\hline Revista de Carreira E Pessoas & 1 & PUC & 1,41 \\
\hline Revista Gestão \& Produção & 1 & UFSCAR & 1,41 \\
\hline Revista Holos & 1 & IFRN & 1,41 \\
\hline Revista Administração em Diálogo & 1 & PUC & 1,41 \\
\hline Revista de Administração e Empresas (RAE) & 1 & FGV & 1,41 \\
\hline Revista Exacta & 1 & UNINOVE & 1,41 \\
\hline Revista Brasileira de Gestão de Negócios & 1 & FECAP & 1,41 \\
\hline Revista Eletrônica de Ciência Administrativa & 1 & CNEC & 1,41 \\
\hline Revista Eletrônica de Administração (Read) & 1 & UFRGS & 1,41 \\
\hline Revista Famecos - Mídia, Cultura e Tecnologia & 1 & PUC & 1,41 \\
\hline Revista Brazilian Journal of Development & 1 & IEN & 1,41 \\
\hline Revista Teoria e Prática em Administração & 1 & UFPB & 1,41 \\
\hline TOTAL & 71 & & 100,00 \\
\hline
\end{tabular}

Fonte: Dados da Pesquisa

A Figura 2 apresenta a publicação regionalizada dos artigos. A região Sudeste foi a maior responsável pela produção acadêmica sobre Governança Corporativa no período de 2014 a 2018, publicando 29 artigos (40,84\%), de toda produtividade científica sobre o tema. A região Sul publicou 24 artigos e obteve um percentual de $33,80 \%$ de produtividade, enquanto as 
regiões Nordeste e Norte publicaram $16(22,54 \%)$ e 2 artigos (2,82\%), respectivamente. A região Centro-Oeste não publicou artigos sobre o tema, na amostra considerada.

Sidone, Haddad e Mena-Chalco (2016) observaram que há diferenças acentuadas entre as distribuições regionais brasileira da produção e as configurações espaciais das redes de cada área do conhecimento. Cruz e Chaimovich (2010), Suzigan e Albuquerque (2011), Sidone, Haddad e Mena-Chalco (2016) discutem a necessidade de promover a propagação do conhecimento dos grandes centros urbanos do Sudeste para outras regiões menos privilegiadas. Possivelmente, as regiões Sudeste e Sul despontam como as maiores produtoras de artigos em virtude de concentrarem universidades e institutos de pesquisa consolidados historicamente.

Figura 2 - Artigos publicados por região

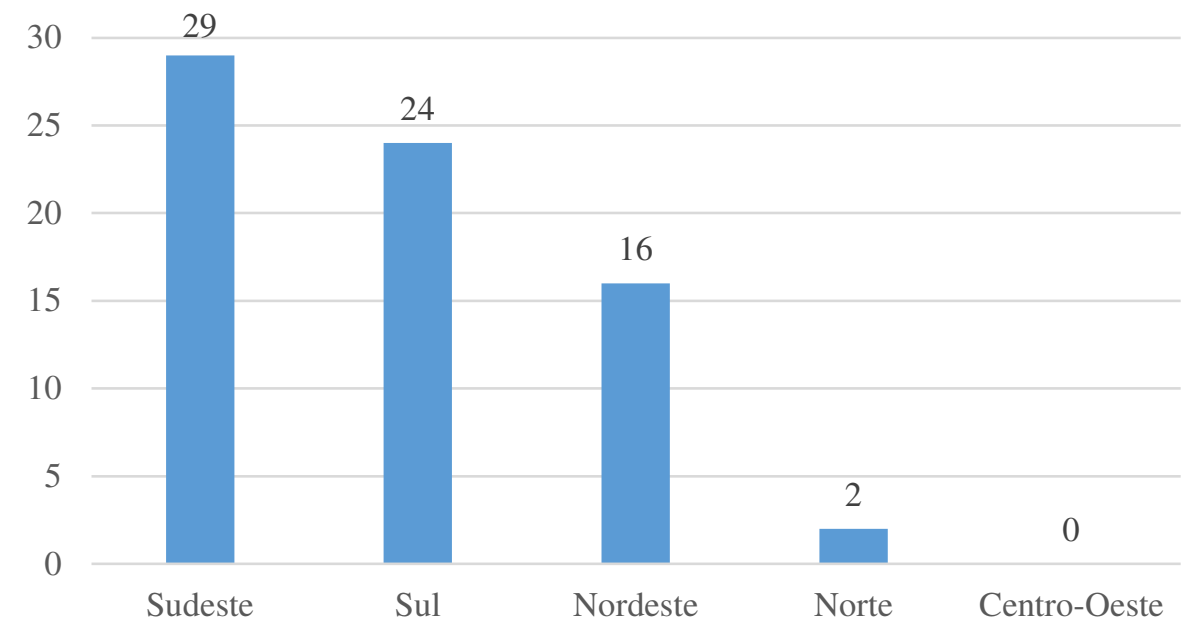

Fonte: Dados da Pesquisa

Na Figura 3, pode-se perceber os autores que realizaram mais publicações sobre o tema Governança Corporativa no período de 2014 a 2018. Destacam-se entre os 198 autores analisados: Henrique César Melo Ribeiro com 5 artigos publicados; Augusto César de Aquino Cabral, Orleans Silva Martins e Fernando Maciel Peixoto com 3 publicações cada. Deste modo, apenas 4 autores produziram mais de 2 artigos científicos sobre o tema nos cinco anos de pesquisa, o que representa cerca de $2 \%$ do total de autores analisados.

Figura 3 - Produção científica por autor

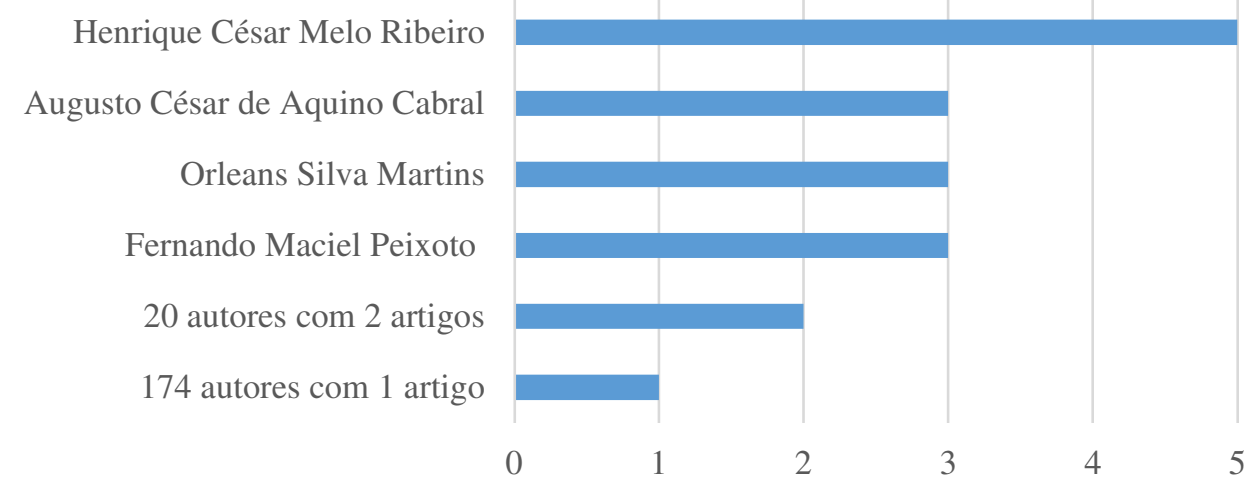

Fonte: Dados da Pesquisa 
Os resultados obtidos são semelhantes aos de Ferreira et al (2019). Os autores comentam que boa parte das publicações é produzida por um ou dois autores por artigo e um grande número de autores possui pouca produção científica sobre o tema. Sendo assim, de acordo com os dados da pesquisa, pode-se confirmar essa constatação, tendo em vista que $87,88 \%$ dos autores produziram apenas um artigo.

$\mathrm{Na}$ análise da pesquisa foram identificadas 23 IES que estavam vinculadas as publicações sobre Governança Corporativa no período de 2014 a 2018. A Figura 4 demonstra que 4 instituições detêm 47,89\% de toda publicação do período. Sendo elas: UFSC (Universidade Federal de Santa Catarina) com 12 publicações, USP (Universidade de São Paulo) com 11 publicações, UNEB (Universidade do Estado da Bahia) com 6 publicações e UFPB (Universidade Federal da Paraíba) com 5 publicações sobre o assunto. Em seguida, vêse que 4 IES publicaram 4 artigos cada, representando 22,53\% da produtividade; 6 IES publicaram 2 artigos cada, representando 16,90\% da produtividade do período e, por fim, 9 IES publicaram um artigo cada, sendo responsáveis por $12,68 \%$ dos artigos publicados sobre Governança Corporativa durante os 5 anos de estudo.

Figura 4 - Produção científica por IES

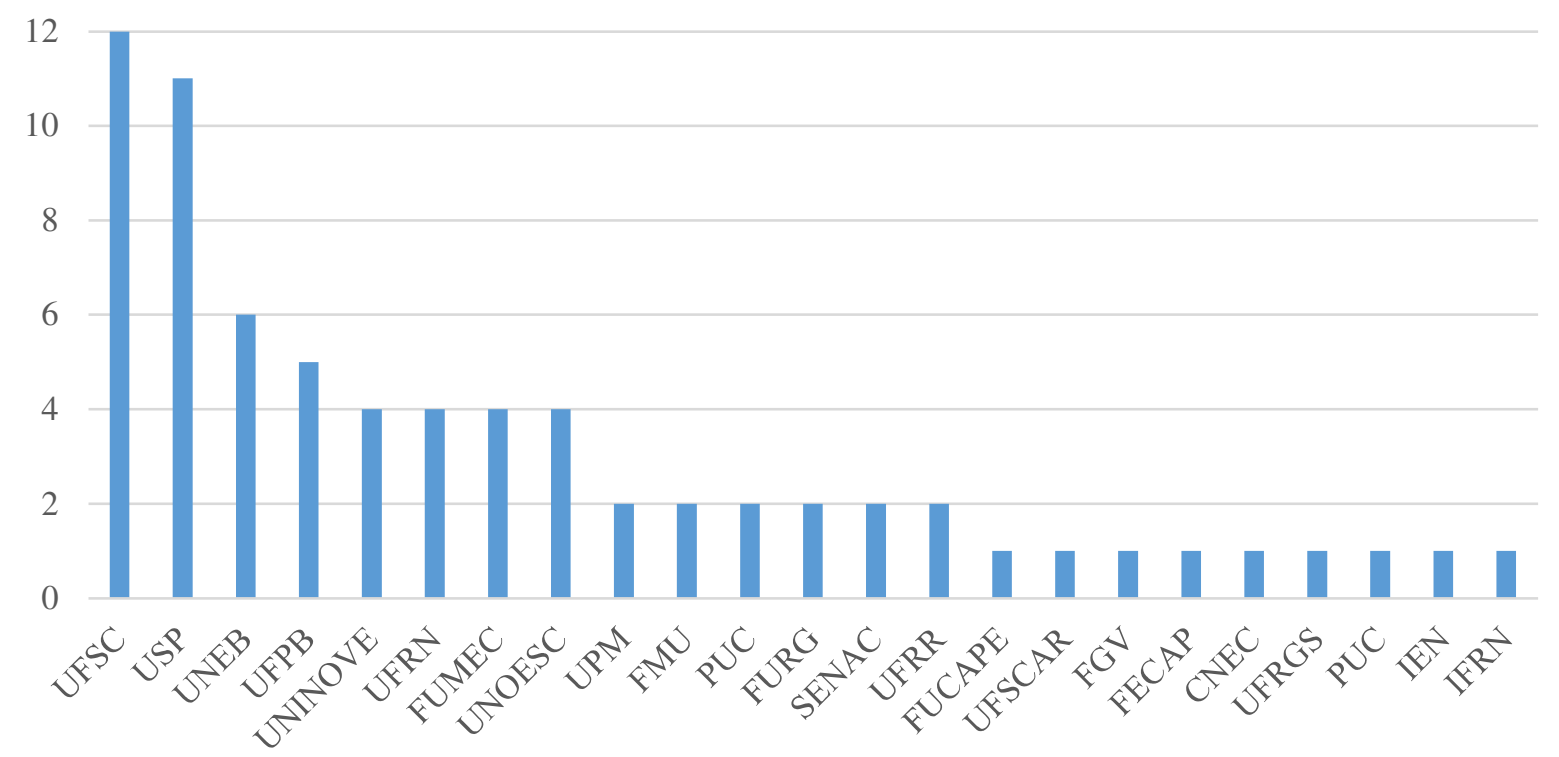

Fonte: Dados da Pesquisa

Quanto ao tipo de abordagem do problema, o que se mostrou predominante nos artigos pesquisados foi a abordagem quantitativa, sendo responsável por $66,2 \%$ de todos os artigos sobre Governança Corporativa no período de 2014 a 2018, enquanto a qualitativa aparece com $22,54 \%$ e a abordagem quali-quanti detém apenas $11,26 \%$ da produtividade científica sobre o assunto. Esse resultado está alinhado à tendência atual das pesquisas sobre o tema governança (Ferreira et al, 2019).

$\mathrm{Na}$ Figura 5 pode-se perceber que apenas no ano de 2018 a metodologia quantitativa não se manteve na liderança quanto aos outros tipos de abordagem. 
Figura 5 - Distribuição por abordagem metodológica

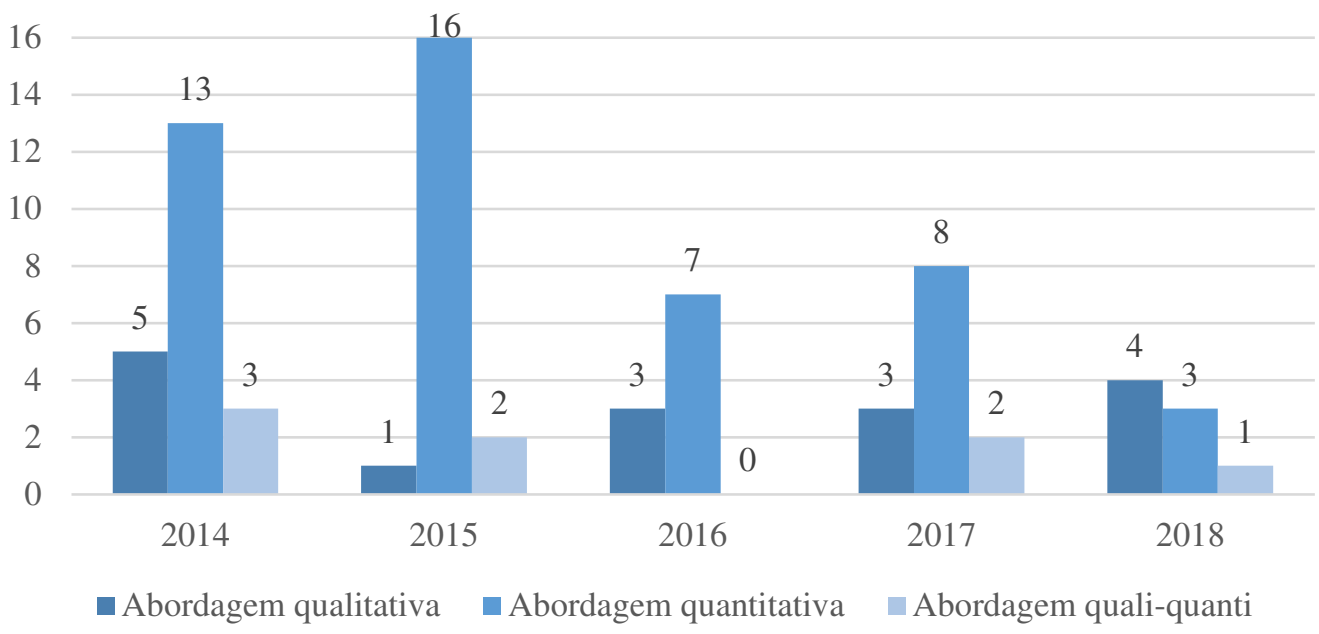

Fonte: Dados da Pesquisa

Pesquisas anteriores, com foco na produção científica sobre Governança Corporativa, foram desenvolvidas de modo correlato ao modelo de pesquisa bibliométrica aplicado neste artigo, a exemplo de Mazzioni et al (2015) que teve como objetivo identificar o perfil das publicações nos periódicos e congressos da área contábil, no período de 2000 a 2012, sobre governança corporativa. O citado artigo mostrou que o ano de 2006 representou um aumento significativo no número de artigos produzidos (13 artigos) e o ano de 2011 foi, até então, o ápice da produtividade (com 16 publicações).

Sendo assim, vê-se de acordo com a pesquisa do presente artigo que houve um crescimento ainda maior nos anos de 2014 e 2015, que até o momento são os anos de maior produtividade com 21 e 19 artigos respectivamente. Porém, pode ter sido iniciada, a partir de então, a estagnação ou esgotamento do tema, tendo em vista o declínio da produtividade científica sobre Governança Corporativa no período estudado.

Nota-se que há uma concentração tanto de regiões quanto de periódicos e Instituições de Ensino Superior na produtividade científica sobre o tema. A pesquisa mostrou que as regiões Sul e Sudeste são responsáveis por quase $75 \%$ de toda a produtividade sobre governança corporativa no período e que apenas 3 revistas são responsáveis por quase $30 \%$ de toda produção científica sobre governança corporativa, sendo duas delas vinculadas a IES pertencentes às regiões Sul e Sudeste.

Percebe-se que existe uma gama enorme de autores $(87,88 \%)$ que são responsáveis apenas pela publicação de um único artigo, o que mostra que não há tendência de monopolização sobre assunto por parte dos autores. Apenas um autor obteve destaque e publicou mais do que 3 artigos. A quantidade de autores por artigo mais comumente encontrada é de 3 autores, representando 32\% dos artigos estudados nesta pesquisa.

Assim, frente ao assunto tratado da necessidade de capacitação do gestor, que deve dominar o conhecimento sobre as transações complexas e não apenas seguir as regras preestabelecidas e a importância do tratamento igualitário entre diferentes interessados, buscase maior clareza ao tratar as transações com partes relacionadas. Essa clareza envolve divulgar as políticas que orientam transações em que haja controle societário ou econômico, bem como demonstrar que as operações são feitas em condições usuais de mercado.

Uma discussão relevante também é referente ao compliance (organização formal, conforme as regras e os processos implementados, e o empenho para cumpri-los). Essa é uma tendência da governança corporativa que está intimamente conectada à transparência e tem ganhado especial valor com a publicação da Lei Anti-Corrupção (Lei n ${ }^{\circ}$ 12.846/2013). O tema 
Compliance vem ganhando um espaço importante nas empresas para tornar as operações mais rápidas, econômicas e seguras.

\section{CONSIDERAÇÕES FINAIS}

Como visto, o objetivo do trabalho foi verificar a evolução da produção acadêmica sobre governança corporativa, no período de 2014 a 2018, delimitada aos periódicos brasileiros das áreas de administração e contabilidade.

O ano que apresenta o maior número de publicações foi o ano de 2014, com 21 artigos publicados. Porém, foi observado um declínio da produção científica no período estudado, o que pode sugerir que o tema pode ter entrado em um período de estagnação ou esgotamento.

A regiões Sul e Sudeste foram responsáveis pela maior produção acadêmica sobre Governança Corporativa, o que mostra uma certa monopolização do conhecimento e a necessidade de que as demais regiões desenvolvam mais ciência e agreguem conhecimento. Essa monopolização se estende também aos periódicos e às Instituições de Ensino Superior na produtividade científica sobre o tema. Sendo poucos os periódicos detentores das publicações sobre o tema, concentrados em IES do Sul e Sudeste. A maioria dos autores analisados foi responsável apenas pela publicação de um único artigo, tendo apenas um autor obtido grande destaque, publicando mais de 3 artigos. A quantidade de autores por artigo mais comumente encontrada foi de 3 autores, sendo a maioria das pesquisas científicas realizadas através da abordagem quantitativa.

Há uma tendência em Governança de tratar de assuntos relacionados a necessidade de capacitação do gestor, que deve dominar o conhecimento sobre as transações complexas e não apenas executar trabalhos burocráticos; de dar ênfase no compliance e de criar e acompanhar novos índices que objetivam diferenciar empresas com melhores práticas de governança corporativa.

Uma limitação da pesquisa é que ela não pode ser generalizada, sendo restrita ao período analisado. Outra limitação ao trabalho foi a restrição às palavras-chaves Governança Corporativa, tendo em vista que se houver uma ampliação de palavras relacionadas ao tema pode haver maior aprofundamento da pesquisa. Deve-se considerar também como limitação o foco dado apenas às revistas brasileiras e ao fato de haver subjetividade na análise e interpretação dos dados.

Para futuros estudos seria interessante a ampliação das palavras-chaves utilizadas no filtro das pesquisas; a ampliação dos periódicos analisados, podendo abarcar outros países e autores com diferentes culturas; aprofundamento sobre a estagnação do tema, se irá se manter desta forma e quais as suas causas; bem como a análise de novas perspectivas que possibilitem o aprofundamento do tema, em especial aquelas que dialoguem com a ciência contábil e áreas afins.

\section{REFERÊNCIAS}

BACH, T. M.; KUDLAWICZ, C.; SILVA, E. D. Influência da estrutura de governança corporativa na eficiência financeira: evidências de empresas brasileiras de capital aberto. Revista Iberoamericana de Estratégia, v. 14, p. 41-62, 2015. 
BARNEY, J.; HESTERLY, W. Economia das organizações: entendendo a relação entre as organizações e a análise econômica. In: Handbook de estudos organizacionais. São Paulo: Atlas, 2004.

BERLE, A.; MEANS, G. The modern corporation and private property. New York: Macmillan, 1932.

BOLSA DE VALORES DE SÃO PAULO - B3. Disponível em: http://www.b3.com.br. Acesso em: 10 ago. 2019.

BRASIL. Lei n ${ }^{\circ}$ 6.404, de 15 de dezembro de 1976. Dispõe sobre as Sociedades por Ações. Portal da Legislação, Brasília. Disponível em: http://www.planalto.gov.br/ccivil_03/LEIS/L6404consol.htm. Acesso em: 10 ago. 2019.

BRASIL. Lei $n^{\circ} 12.846$, de $1^{\circ}$ de agosto de 2013. Dispõe sobre a responsabilização administrativa e civil de pessoas jurídicas pela prática de atos contra a administração pública, nacional ou estrangeira, e dá outras providências. Portal da Legislação, Brasília. Disponível em: http://www.planalto.gov.br/ccivil_03/_ato2011-2014/2013/lei/112846.htm. Acesso em: 10 ago. 2019.

CHAGAS, J. F. Governança corporativa: aplicabilidade do conceito, dos princípios e indicadores à gestão de pequenas e médias organizações. $C E P$, v. 60, n. 180, 2007.

CORREIA, L. F. Um Índice de Governança para Empresas no Brasil. 2008. Tese (Doutorado em Administração) - Universidade Federal de Minas Gerais, Belo Horizonte, 2008.

COMISSÃO DE VALORES MOBILIÁRIOS. Instrução CVM no 586, de 8 de junho de 2017. Altera e acrescenta dispositivos à Instrução CVM n 480, de 7 de dezembro de 2009.

Disponível em:

http://www.cvm.gov.br/export/sites/cvm/legislacao/instrucoes/anexos/500/inst586.doc.

Acesso em: 10 ago. 2019.

COSTA, R. R. R. A destinação do lucro das companhias abertas brasileiras com as melhores práticas de governança corporativa e o seu impacto na rentabilidade do acionista. 2013.

Dissertação (Mestrado em Contabilidade) - Universidade de São Paulo, Ribeirão Preto, 2013.

CRUZ, C. H. B.; CHAIMOVICH, H. Brazil. In: United Nations Educational Scientific and Cultural Organization (Org.). Science Report 2010. Paris: Unesco, 2010.

DEMIRBAS, D; YUKHANAEV, A. Independence of board of directors, employee relation and harmonisation of corporate governance: Empirical evidence from Russian listed companies. Employee Relations, v. 33, n. 4, p. 444-471, 2011.

FERREIRA, R. M.; LIMA, S. L. L.; GOMES, A. R. V.; MELLO, G. R. Governança Corporativa: um estudo bibliométrico da produção científica entre 2010 a 2016. Revista Organizações em Contexto, v. 15, n. 29, p. 323-342, 2019.

INSTITUTO BRASILEIRO DE GOVERNANÇA CORPORATIVA. Disponível em: https://www.ibgc.org.br/. Acesso em: 2 ago. 2019. 
IUDÍCIBUS, S.; LOPES, A. B. Teoria Avançada da Contabilidade. São Paulo: Atlas, 2004.

JENSEN, M.; MECKLING, W. Theory of the firm: managerial behavior, agency costs and ownership structure. Journal of Financial Economics, v. 3, n. 4, p. 305-360, 1976.

KLAPPER, L; LOVE, I. Corporate governance, investor protection, and performance in emerging markets, Journal of Corporate Finance, v. 10, n. 5, p. 703-728, 2004.

MACHADO, D. G.; FERNANDES, F. C.; BIANCHI, M. Teoria da Agência e Governança Corporativa: reflexão acerca da Subordinação da Contabilidade à Administração. Revista de Auditoria, Governança e Contabilidade, v. 4, n. 10, p. 39-55, 2016.

MARTINEZ, A.L. Agency Theory na Pesquisa Contábil. In: ENCONTRO NACIONAL DOS PROGRAMAS DE PÓS GRADUAÇÃO EM ADMINISTRAÇÃO, 22., 1998, Foz do Iguaçu. Anais[...]. Foz do Iguaçu, 1998.

MAZZIONI, S.; FOLETTO, E. P.; GUBIANI, C. A.; KRUGER, S. D. Governança Corporativa: análise bibliométrica do período de 2000 a 2012. Revista de Administração, Ciências Contábeis e Sustentabilidade, v. 5, p. 1-21, 2015.

MERCHANT, K. A.; VAN DER STEDE, W. A. Management Control Systems: performance measurement, evaluation and incentives. 2nd ed. Prentice Hall, Pearson Education Limited, 2007.

MORAES, C. Z. Governança Corporativa: uma visão sob a Teoria da Agência. Revista de Ciências Gerenciais, v. 19, p. 34-40, 2015.

OLIVEIRA, U. A. Relação entre tipos de controle gerencial e artefatos de contabilidade gerencial. 2011. Dissertação (Mestrado em Ciências Contábeis) - Fundação Instituto Capixaba de Pesquisa em Contabilidade, Economia e Finanças - Fucape, Vitória, 2011.

OLIVEIRA, M. C. S.; MORAIS, H. A. R.; SOUZA NETO, M. O.; LIMA, J. H. Governança corporativa: uma análise do desempenho das companhias abertas brasileiras listadas nos níveis da BM\&FBOVESPA. Revista de Administração de Roraima, v. 7, n. 2, p. 402-425, 2017.

RIBEIRO, H. C. M.; SANTOS, M. C. Perfil e evolução da produção científica do tema governança corporativa nos periódicos Qualis/Capes nacionais: uma análise bibliométrica e de redes sociais. Contabilidade, Gestão e Governança, v. 18, n. 3, p. 4-27, 2015.

SONZA, I. B.; KLOECKNER, G. O. A Governança Corporativa Influencia a Eficiência das Empresas Brasileiras? Revista de Contabilidade e Finanças, v. 25, n. 65, p. 145-160, 2014.

SIDONE, O. J. G.; HADDAD, E. A.; MENA-CHALCO, J. P. A ciência nas regiões brasileiras: evolução da produção e das redes de colaboração científica. TransInformação, v. 28, n. 1, p. 15-32, 2016.

SUZIGAN, W.; ALBUQUERQUE, E. The underestimated role of universities for the Brazilian system of innovation. Brazilian Journal of Political Economy, v. 31, n. 1, p. 3-30, 2011. 